\title{
ARTICLE \\ Increased BBB permeability contributes to EGCG-caused cognitive function improvement in natural aging rats: pharmacokinetic and distribution analyses
}

\author{
Bin-bin Wei ${ }^{1}$, Ming-yan Liu ${ }^{1}$, Xin Zhong ${ }^{1}$, Wei-fan Yao ${ }^{1}$ and Min-jie Wei ${ }^{1}$
}

\begin{abstract}
Previous studies report that (-)-epigallocatechin-3-gallate (EGCG), the most abundant polyphenolic ingredient in green tea, has high efficacy against Alzheimer's disease (AD) in various in vivo and in vitro models. However, as a water-soluble component, how EGCG exerts its anti-AD effects in the brain was not elucidated. In the present study, we investigated the anti-AD mechanisms of EGCG in natural aging rats with cognitive impairments (Cls) assessed using Morris water maze. The rats were treated with EGCG (100 mg/kg per day, intragastrically) for 4 weeks. The expression of $\beta$-amyloid $\left(A \beta_{1-42}\right)$ in the brain was detected with immunohistochemical staining. We showed that EGCG administration significantly ameliorated the $\mathrm{Cl}$ in the aging rats with $\mathrm{Cl}$ and decreased $A \beta_{1-42}$ plaque formation in their brains. Then we used an efficient ultra-performance liquid chromatography-tandem mass spectrometer method to evaluate EGCG concentrations in rat plasma and tissue distribution. We found that EGCG absorption was significantly increased in the aging with $\mathrm{Cl}$ group compared with control young rats. After oral administration of EGCG (100 mg), EGCG could not be detected in the brain tissues of control young rats, but it was found in the brain tissue of aging rats with CI. By using Evans Blue assay, transmission electron microscopy, and Western blotting assay, we demonstrated that the permeability of blood-brain barrier (BBB) was significantly increased in aging rats with $\mathrm{Cl}$. These results suggest that the permeability change of BBB is the physiological structural basis for EGCG treatment to improve learning and memory, thus providing a solid evidence for EGCG druggability in antiAD therapeutic field.
\end{abstract}

Keywords: EGCG; Alzheimer's disease; natural aging rats; cognitive impairments; $A \beta_{1-42}$ plaque; drug distribution; blood brain barrier

Acta Pharmacologica Sinica (2019) 40:1490-1500; https://doi.org/10.1038/s41401-019-0243-7

\section{INTRODUCTION}

Alzheimer's disease (AD) is an age-related progressive neurodegenerative disease that is clinically characterized by cognitive impairments $(\mathrm{Cls})$ and pathologically characterized by senile plaques consisting of $\beta$-amyloid $\left(A \beta_{1-42}\right)$ peptide deposits and neuronal loss [1-4]. AD has become a serious threat to the health and quality of life of the elderly population $[5,6]$. According to the AD international annual report [7], by 2030 , the AD population will rise sharply to 65.69 million. As the most abundant polyphenolic constituent in green tea, (-)-epigallocatechin-3-gallate (EGCG) has been reported to have potent iron-chelating, antioxidant, antiinflammatory anticancer effects, and especially, neuroprotective effects [8-11]. Previous studies have reported that EGCG treatment significantly reduces $A \beta_{1-42}$ generation in a human-derived neuroblastoma cell line (SH-SY5Y) and markedly improves cognitive deficits in different AD animal models [12-16]. However, as a water-soluble compound, how EGCG elicits the anti-AD effects in the central nervous system (CNS) has not been clearly explained.

Thus, EGCG has been chosen as the object of research in the present study; we developed a selective and selective ultra-performance liquid chromatography-tandem mass spectrometer (UPLC-MS/MS) method for the determination of EGCG in normal and $\mathrm{Cl}$ group rat plasma and tissues, so as to study the compared results of pharmacokinetics and tissue distribution. Based on the above research, related possible mechanism was discussed. The blood-brain barrier (BBB) is composed of a continuous layer of brain capillary endothelial cells together with pericytes, a basal lamina, and astroglial cells. In the endothelial cells, the tight junctions (TJs) form a metabolic and physical barrier restricting the movement of macromolecules between the blood and brain to maintain cerebral homeostasis. So, by using the Evans Blue (EB) assay, transmission electron microscopy (TEM) and Western blotting assay, we demonstrated that the permeability of BBB was significantly increased in aging rats with $\mathrm{Cl}$.

Therefore, in the present study, we found the different pharmacokinetic and distribution patterns between young rats and aging rats with $\mathrm{Cl}$. These differences indicated that an increase in BBB permeability plays an important role in the anti-AD efficacy of EGCG treatment demonstrated by cognitive improvement, providing powerful evidence for the use of EGCG as an anti$A D$ therapeutic drug.

${ }^{1}$ School of Pharmacy, China Medical University, Shenyang 110122, China

Correspondence: Min-jie Wei (minjie_wei@163.com)

Received: 17 December 2018 Accepted: 25 April 2019

Published online: 15 May 2019 


\section{MATERIALS AND METHODS}

Animals and treatment

Male pathogen-free Sprague-Dawley rats were kindly provided by the Experimental Animal Center of China Medical University (Shenyang, China). The animal study was carried out in accordance with the Guideline for Animal Experimentation of China Medical University, and the protocol was approved by the Animal Ethics Committee of the institution. One-year-old natural aging rats $(400-450 \mathrm{~g})$ and 6-week-old young rats $(250-280 \mathrm{~g})$ were adopted for our study. Natural aging rats with $\mathrm{Cl}$ were screened after Morris water maze (MWM) evaluation.

EGCG (Sigma-Aldrich Chemicals Pvt. Ltd., USA) was dissolved in distilled water at a concentration of $0.2 \mathrm{mg} / \mathrm{mL}$. Distilled water was used as the vehicle. EGCG or vehicle was administered by intragastric administration (100 mg/kg body weight) at 9:00 a.m. once daily for 4 weeks to confirm the anti-AD efficacy of EGCG. The EGCG group received EGCG $(100 \mathrm{mg} / \mathrm{kg}$ per day) intragastrically for 4 weeks; the aging with $\mathrm{Cl}$ groups and control groups received the same volume of vehicle for 4 weeks. After evaluation of the behavioral test and immunohistochemical staining, the rats in the control and aging with $\mathrm{Cl}$ groups were used for the pharmacokinetic and distribution study and BBB-related determinations.

\section{MWM test}

The cognitive performance of 6-week-old rats and 1-year-old natural aging rats was evaluated in the MWM, including the navigation test and probe trial. Aging rats with $\mathrm{Cl}$ were screened for further EGCG studies, such as its anti-AD efficacy, pharmacokinetics, distribution, and BBB permeability. Two batches of MWM tests were carried out: one for screening the aging rats with $\mathrm{Cl}$ and the other for evaluating the cognitive performance after EGCG treatment.

The MWM is a stainless-steel circular water tank $120 \mathrm{~cm}$ diameter $\times 50 \mathrm{~cm}$ height) equipped with a platform $(10 \mathrm{~cm}$ diameter) placed in the second quadrant and submerged $0.5-1$ $\mathrm{cm}$ below the surface of water. In brief, rats were allowed to swim freely for $1 \mathrm{~min}$ without the platform to adjust themselves to the circumstances on the baseline day (day 0). From the first day to the fifth day, the platform was placed under the water in the tank for navigation tests, and each rat was subjected to four trials per day at an interval of $60 \mathrm{~s}$ for spatial acquisition. Different start locations were used on each trial. If a rat failed to find the platform within $60 \mathrm{~s}$, it would be picked up and placed on the platform for $60 \mathrm{~s}$. For each trial, the latency and the path length by which the rat found the hidden platform were recorded. On the sixth day, a probe trial was performed to assess memory consolidation. The platform was removed from the tank, and the rats were allowed to swim freely for $60 \mathrm{~s}$. The start position was novel and was $180^{\circ}$ from the original platform position so that the spatial preference reflected the memory of the goal location rather than a memory of a specific swim path. The frequency that each rat passed over the goal location (where the platform was previously located) and the percentage of time spent in the target quadrant were recorded. All data were obtained by a video tracking system (Chengdu Taimeng Tech. Co. Ltd, Chengdu, China).

\section{Immunohistochemistry}

Twenty-four hours after the behavioral tests for evaluating the anti-AD efficacy of EGCG, six rats in each group were anesthetized with sodium pentobarbital $(50 \mathrm{mg} / \mathrm{kg}$ ) by intraperitoneal administration and then transcardially perfused with normal saline followed by $4 \%$ paraformaldehyde solution. The right hemisphere of brains was removed and postfixed in $4 \%$ paraformaldehyde overnight at $4{ }^{\circ} \mathrm{C}$, and routine paraffin sections $(4 \mu \mathrm{m})$ were prepared for immunohistochemical staining. Paraffin-embedded slices of cerebral cortex and hippocampus tissues were incubated overnight at $4{ }^{\circ} \mathrm{C}$ with a primary rabbit anti-A $\beta_{1-42}$ antibody (1:500,
Thermo). After the sections were rinsed, they were incubated in biotinylated goat anti-rabbit lgG $\left(1: 200\right.$, Maixin) at $37^{\circ} \mathrm{C}$ for $30 \mathrm{~min}$, followed by streptavidin-peroxidase conjugate (1:200, Maixin) at $37^{\circ} \mathrm{C}$ for $30 \mathrm{~min}$. The sections were developed with 3, $3^{\prime}-$ diaminobenzidine in a chromogen solution and counterstained with hematoxylin. Images were obtained using an Olympus BX-61 microscope (Tokyo, Japan) and digitized using an attached Spot flex imaging system (Tokyo, Japan). Data were analyzed using the Image-Pro Plus 6.0 analysis system.

\section{ELISA assay}

After the tissue samples were cut, phosphate-buffered saline (PBS) $(\mathrm{pH}$ 7.2-7.4) was added, and the samples were rapidly frozen with liquid nitrogen and maintained at $2-8{ }^{\circ} \mathrm{C}$. After the samples were thawed, PBS was added, and the samples were homogenized by hand and centrifuged for $20 \mathrm{~min}$ at $10000 \times \mathrm{g}$, followed by removal of the supernatant. The sample was diluted with the standard, and the mixture was placed in 10 standard wells on coated enzyme-linked immunosorbent assay (ELISA) plates at a density of $600,400,200,100$, or $50 \mu \mathrm{g} / \mathrm{L}$. After the plate was sealed with a closure plate membrane, the sample was incubated for $30 \mathrm{~min}$ at $37^{\circ} \mathrm{C}$. After the liquid was discarded, the samples were washed, and enzyme was added, followed by another incubation and wash. The samples were then stained, and $50 \mu \mathrm{L}$ Stop Solution was added to each well to stop the reaction (the blue color changing to a yellow color). Taking the blank well as zero, the absorbance of each well was read at $450 \mathrm{~nm}$ within $15 \mathrm{~min}$ of the addition of the Stop Solution.

\section{EB assay}

A $2 \%$ EB saline solution was used to determine the standard curve. Six rats in the control and aging with $\mathrm{Cl}$ groups were injected with $2 \%$ EB saline solution via the tail vein. After $2 \mathrm{~h}$, whole-brain tissues were collected, homogenized with methanol (1:4), and immediately centrifuged. The absorbance was detected at $619 \mathrm{~nm}$.

\section{Transmission electron microscopy}

Brain tissues $(1 \mathrm{~mm} \times 1 \mathrm{~mm} \times 1 \mathrm{~mm})$ in the control and aging with $\mathrm{Cl}$ groups ( $n=3$ per group) were fixed in $2.5 \%$ glutaraldehyde, washed with PBS four times, and fixed with $2 \%$ osmium tetroxide. After dehydration by a graded series of ethanol, the tissues were embedded in epoxy resin, ultrathin sliced, and double-stained with uranyl acetate and lead citrate. Under the condition of $80 \mathrm{kV}$ with JEM-1200 EX transmission electron microscopy (TEM), changes in the opening of TJs were observed.

\section{Western blotting}

The left hemisphere of brains in each group was rapidly removed, and the hippocampus and cerebral cortex were dissected and stored at $-80^{\circ} \mathrm{C}$ for Western blotting. The samples were minced into small pieces, homogenized on ice in precooled RIPA buffer containing $150 \mathrm{mM} \mathrm{NaCl}, 50 \mathrm{mM}$ Tris- $\mathrm{HCl}$ (pH 8.0), 1\% NP-40, 0.5\% sodium deoxycholate, $0.1 \%$ sodium dodecyl sulfate (SDS), $0.1 \%$ phenyl methyl sulfonyl fluoride, and incubated overnight at $4^{\circ} \mathrm{C}$. The homogenate was centrifuged at $12000 \times g$ for 30 min at $4{ }^{\circ} \mathrm{C}$, and the supernatant was collected. Protein qualification was carried out using a BCA kit (Walterson Biotechnology Inc., Beijing, China). The total protein extract ( $25 \mu \mathrm{g}$ per lane) was separated on SDS-polyacrylamide gels and transferred onto polyvinylidene difluoride membranes (Millipore, Billerica, MA, USA). Nonspecific binding sites on the membrane were blocked by PBS containing $0.1 \%$ Tween-20 (PBST) with 5\% bovine serum albumin for $1 \mathrm{~h}$, followed by incubation with rabbit polyclonal primary antibodies against claudin-5, occludin, ZO-1 (1:1000, Sigma, St. Louis, MO, USA), and $\beta$-actin (1:1000, Santa Cruz) overnight at $4{ }^{\circ} \mathrm{C}$. After the membranes were washed with PBST, they were incubated with goat anti-rabbit secondary antibody conjugated to horseradish peroxidase (1:2000; Santa Cruz, Shanghai, China) for $1 \mathrm{~h}$ at room 
Table 1. Optimized MRM parameters for EGCG and IS

\begin{tabular}{llllll}
\hline Compounds & $m / z$ of precursor ion $(\mathrm{Da})$ & $m / z$ of product ion $(\mathrm{Da})$ & Dwell time $(\mathrm{s})$ & Cone voltage $(\mathrm{V})$ & Collision voltage $(\mathrm{eV})$ \\
\hline EGCG & 456.9 & 168.8 & 0.5 & 25 & 12 \\
IS & 152.9 & 108.9 & 0.5 & 60 & 24 \\
\hline
\end{tabular}

MRM multiple reaction monitoring, Is internal standard, EGCG (-)-epigallocatechin-3-gallate

temperature. Immunoreactive bands were visualized using the enhanced chemiluminescent kit $(\mathrm{ECL}+$, Amersham Biosciences, Piscataway, NJ, USA). Bands were measured using Quality One analysis software (Bio-Rad), and the density of each band was normalized to the density of the $\beta$-actin band.

EGCG concentration in rat plasma and other tissues by UPLC-MS/ MS

Instruments and UPLC-MS/MS conditions. The controls and samples were analyzed on ACQUITY UHPLC-Waters Xevo TQ-S. Separations were accomplished on a Thermo Hypersil GOLD (2.1 $\mathrm{mm} \times 100 \mathrm{~mm}, 1.9 \mu \mathrm{m}$ ) (Thermo, USA) with a Thermo guard cartridge at $30^{\circ} \mathrm{C}$. The mobile phase consisted of acetonitrile-water $(20: 80, \mathrm{v} / \mathrm{v})$, which was delivered at a flow rate of $0.4 \mathrm{~mL} / \mathrm{min}$.

The mass spectrometer was operated in the negative ion mode with a Turboion spray source. Table 1 shows the optimized MRM parameters for EGCG and the internal standard (IS). The other ionization parameters were as follows: curtain gas (CUR), 20 (arbitrary units); ion source gas 1, 50 (arbitrary units); ion source gas 2, 50 (arbitrary units); source temperature (TEM), $500^{\circ} \mathrm{C}$; and entrance potential, $10 \mathrm{~V}$. The dwell time of each MRM transition was $200 \mathrm{~ms}$. The full scan product ion spectra of the precursor ions of EGCG and the IS are shown in Fig. 1.

Standard solution and quality control samples. The standard stock solution $(500 \mu \mathrm{g} / \mathrm{mL})$ of the EGCG and IS were prepared with water/acetonitrile $(80: 20, v / v)$ to obtain standard working solutions. Calibration standard solutions were prepared by spiking these working solutions into drug-free rat plasma or brain homogenate to obtain the analyte. EGCG was set at concentrations of $50,100,200,1000,2500,1250$, and $2500 \mathrm{ng} / \mathrm{mL}$. Quality control samples were prepared separately in the same fashion. An IS working solution $(5000 \mathrm{ng} / \mathrm{mL})$ was prepared.

Plasma and brain homogenates ample preparation. Plasma or brain homogenate samples $(200 \mu \mathrm{L})$ were transferred to a $10 \mathrm{~mL}$ centrifuge tube together with $20 \mu \mathrm{L}$ IS solution, $20 \mu \mathrm{L}$ water/ acetonitrile $(80: 20, \mathrm{v} / \mathrm{v})$, and $20 \%$ Vitamin C (VC) solution. After the solution was vortexed for $30 \mathrm{~s}, 2 \mathrm{~mL}$ ethyl acetate was added. The analyte and IS were extracted by vortexing for $5 \mathrm{~min}$ and shaking for $5 \mathrm{~min}$. Then, the samples were centrifuged at $3000 \times g$ for 5 min. The organic layer was quantitatively transferred to a $5 \mathrm{~mL}$ glass tube and evaporated to dryness at $35^{\circ} \mathrm{C}$ under a slight stream of nitrogen. Then, the dried extract was reconstituted in $200 \mu \mathrm{L}$ solvent (water-acetonitrile, 80:20, v/v), followed by injection of a $5 \mu \mathrm{L}$ aliquot into the UPLC-MS/MS system for analysis.

Method validation. The method was fully validated in accordance with US FDA (Food and Drug Administration) guidelines and $\mathrm{ICH}$ (International Council on Harmonisation of Technical Requirements for Pharmaceuticals for Human Use) $[17,18]$ with respect to selectivity, lower limit of quantification, calibration curve, accuracy and precision, recovery, matrix effect, and stability.

Drug administration and sampling. Another 30 rats in both the control group and aging with $\mathrm{Cl}$ group were fasted for $12 \mathrm{~h}$
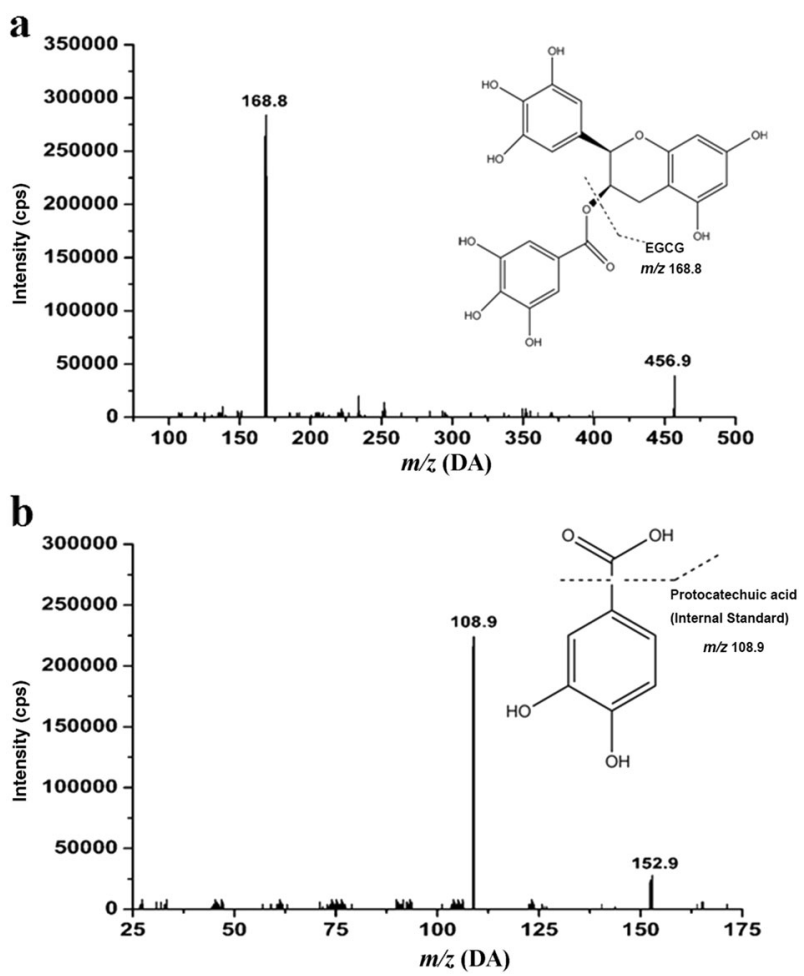

Fig. 1 Full scan product ion of precursor ions of (-)-epigallocatechin-3-gallate (EGCG) (a) and internal standard protocatechuic acid (b)

with free access to water prior to the oral administration of $100 \mathrm{mg} / \mathrm{kg}$ EGCG.

Six rats in both the control group and aging with $\mathrm{Cl}$ group were employed in the pharmacokinetic study. The EGCG concentration in rat plasma samples was determined by UPLC-MS/MS. Blood samples were collected in heparinized tubes via the postorbital venous plexus veins from each rat before administration and 0.17 , $0.33,0.5,1,1.5,2.0,3.0,4.0,5.0,6.0,8.0,10,12$, and $24 \mathrm{~h}$ after administration and were immediately centrifuged and stored at $-20^{\circ} \mathrm{C}$ until analysis.

Twenty-four rats in both the control group and aging with $\mathrm{Cl}$ group were employed in the distribution study. Brain and other tissue samples were collected at 1.0, 2.0, 4.0, and $6.0 \mathrm{~h}$; for each time point, six rats were sacrificed. The EGCG concentration in different tissue samples was determined by UPLC-MS/MS. The brains were removed, washed with residual blood, air dried, and weighed. Brain tissue samples were homogenized with methanol (1:4) and were immediately centrifuged and stored at $-20^{\circ} \mathrm{C}$ until analysis. In the meantime, other rat tissues were collected as described above for the tissue distribution experiment.

Statistical analysis

Data were expressed as the mean \pm standard deviation (SD). Pharmacokinetic parameters were calculated using the DAS 

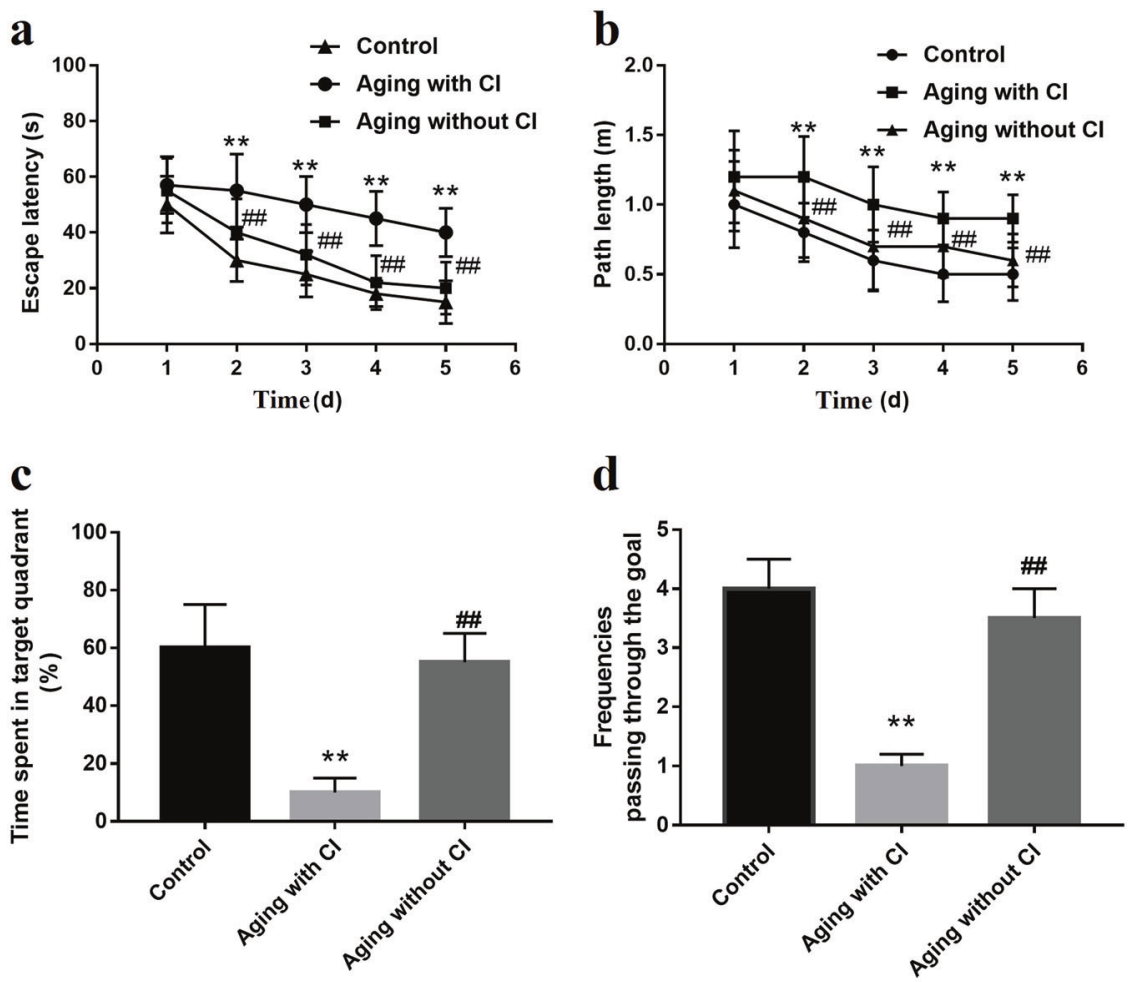

e Control

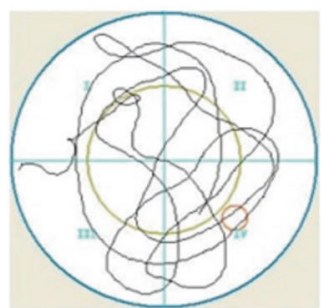

Aging with $\mathrm{Cl}$

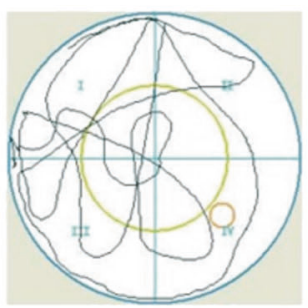

Aging without $\mathrm{Cl}$

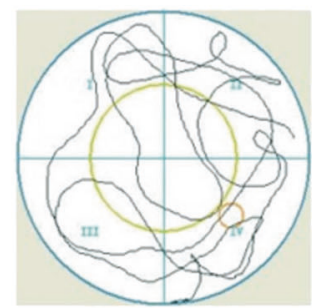

Fig. 2 Natural aging rats with cognitive impairments $(\mathrm{Cls})$ were screened by cognitive performance in Morris water maze (MWM) (control group, $n=45$; aging with cognitive impairments (Cl) group, $n=45$; aging without $\mathrm{Cl}$ group, $n=45$ ). (a) The escape latency to reach the goal in the navigation test of MWM. (b) The path length to reach the goal in the navigation test of MWM. (c) The time spent in target quadrant in the probe trial of MWM. (d) The frequencies of passing through the goal in the probe trial of MWM. (e) The representative locus plot in the probe trial. ${ }^{* *} P<0.01$, compared with the control group; ${ }^{\# \#} P<0.01$, compared with the aging with $\mathrm{Cl}$ group

2.1 software. All statistical analyses were performed using the SPSS statistical software package (Statistical Package for the Social Sciences, version 13.0, SPSS Inc., Chicago, IL, USA). One-way analysis of variance was used to compare the differences among the groups. Two independent-sample $t$ tests were applied to analyze the difference between the control group and the aging group. A $P$ value $<0.05$ was considered significant.

\section{RESULTS}

EGCG treatment ameliorated learning and memory impairment in aging rats with $\mathrm{Cl}$

To distinguish between 1-year-old natural aging rats with and without $\mathrm{Cl}$, we first performed MWM to evaluate the cognitive performance in natural aging rats. Compared with the control group, the aging rats with $\mathrm{Cl}$ exhibited a significantly longer latency and path length to find the goal (Fig. 2a, b) on the 2nd-5th day of the navigation test, and the percentage of time spent in the target quadrant and the frequencies of passing through the goal were lower in the aging rats with $\mathrm{Cl}$ on the sixth day of the probe trial than that in the control rats (Fig. $2 \mathrm{c}-\mathrm{e}$ ). After screening, we included 45 aging rats with $\mathrm{Cl}$ in our further analyses.

Next, we intragastrically administered EGCG $(100 \mathrm{mg} / \mathrm{kg}$ per day) for 4 weeks, and the MWM was used to evaluate the anti-AD efficacy of EGCG. In the MWM navigation tests, compared with the aging with $\mathrm{Cl}$ group, the EGCG-treated group exhibited significant improvements in escape latency and path length $(P<$ 0.01 , Fig. 3a, b), suggesting that EGCG treatment improved the impairments of spatial acquisition in aging rats with $\mathrm{Cl}$. Moreover, in the probe trial, the percentage of time spent in the target quadrant and the frequencies of passing through the goal were significantly higher $(P<0.01$, Fig. $3 c-e)$ than those in the aging with $\mathrm{Cl}$ group. The results suggested that EGCG treatment improved learning and memory performance in aging rats with $\mathrm{Cl}$.

EGCG treatment decelerated $A \beta_{1-42}$ plaque formation in the hippocampus and cortex of aging rats with $\mathrm{Cl}$

The MWM results showed that $\mathrm{Cls}$ in aging rats with $\mathrm{Cl}$ were improved after EGCG treatment. Next, we investigated $A \beta_{1-42}$ plaque formation to ensure the anti-AD efficacy of EGCG treatment. Compared with the aging group, after a 4-week 

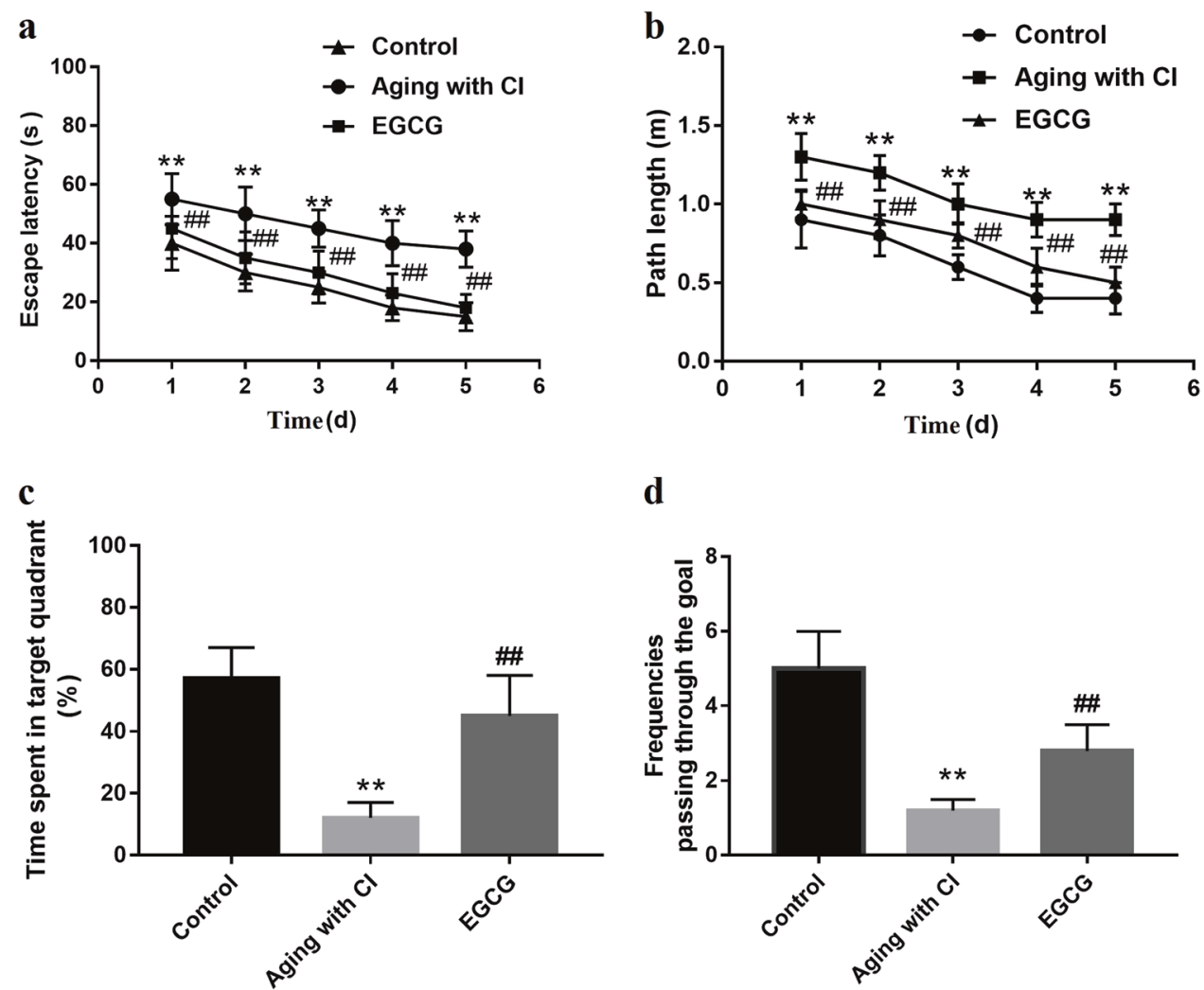

d

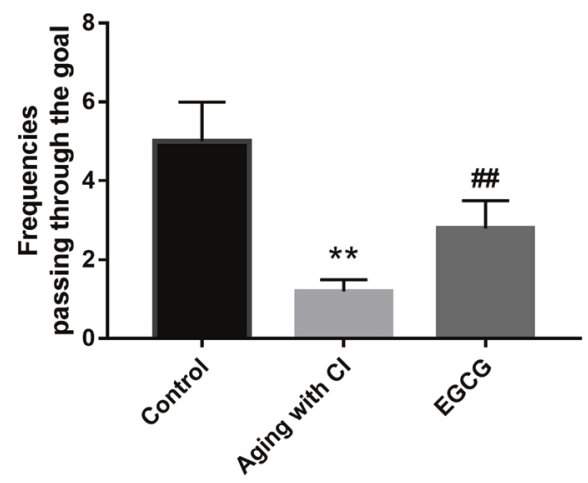

$\mathbf{e}$ Control

Aging with $\mathrm{Cl}$ EGCG
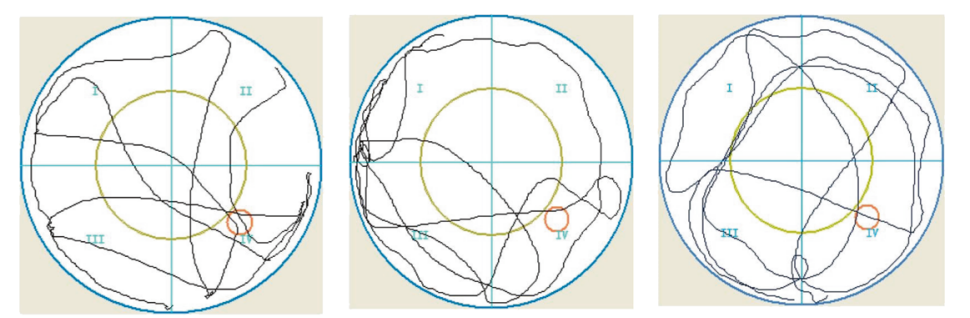

Fig. 3 (-)-Epigallocatechin-3-gallate (EGCG) treatment improved learning and memory performance in aging rats with cognitive impairment (CI) by Morris water maze (MWM) $(n=6)$. a EGCG treatment decreased the escape latency to reach the goal in aging rats with $\mathrm{Cl}$ in the navigation test of MWM. b EGCG treatment shortened path length to reach the goal in aging rats with $\mathrm{Cl}$ in the navigation test of MWM. $\mathbf{c}$ The percentage of the time spent in target quadrant was prolonged after EGCG treatment in aging rats with $\mathrm{Cl}$ in the probe trial of MWM. $\mathbf{d}$ The frequencies of passing through the goal increased after EGCG treatment in aging rats with $\mathrm{Cl}$ in the probe trial of MWM. e The representative locus plot in the probe trial. ${ }^{*} P<0.01$, compared with the control group; ${ }^{\# \#} P<0.01$, compared with the aging with $\mathrm{Cl}$ group

administration of EGCG, the EGCG group exhibited significantly lower $A \beta_{1-42}$ expression in the hippocampus and cortex $(P<0.01$, Fig. 4), suggesting that EGCG treatment decelerated the overexpression of $A \beta_{1-42}$ in aging rats with $\mathrm{Cl}$ and confirming the antiAD efficacy of EGCG.

ELISA showed that EGCG treatment reduced the $A \beta$ levels in aging rats with $\mathrm{Cl}$

ELISA results showed that $A \beta$ was reduced by EGCG treatment. Compared with the aging group, after a 4-week administration of EGCG, the EGCG group exhibited significantly lower $A \beta$ content $(P<0.05$, Fig. 5$)$, suggesting that EGCG treatment decelerated $A \beta$ in aging rats with $\mathrm{Cl}$ and confirming its anti-AD efficacy.

EGCG exhibited different pharmacokinetic and distribution characteristics in the control and aging with $\mathrm{Cl}$ groups

The mechanism by which EGCG, as a water-soluble component, elicits an anti-AD effect in the CNS remains a puzzle. Therefore, we first investigated the pharmacokinetic and distribution characteristics in the control and aging with $\mathrm{Cl}$ groups to reveal the functional basis of the anti-AD mechanism of EGCG.

To analyze the EGCG rat plasma concentration and tissue distribution, an efficient UPLC-MS/MS method was developed and validated. The typical chromatograms of blank brain homogenate, blank brain homogenate spiked with EGCG and IS, and brain homogenate sample $2 \mathrm{~h}$ after administration of EGCG at a dose of $100 \mathrm{mg} / \mathrm{kg}$ are shown in Fig. 6 . The retention time of EGCG was $1.3 \mathrm{~min}$ and that of IS was $1.1 \mathrm{~min}$, indicating that no endogenous interference was observed at the retention time of EGCG and IS. Standard calibration curves with good linearity were built for detecting the EGCG concentrations in the rat plasma and tissue homogenate (as shown in Table 2). The lower limits of quantification of EGCG in the rat plasma and tissues were 5 and $0.5 \mathrm{ng} / \mathrm{mL}$, respectively. The accuracy, precision, recovery, and matrix effect of EGCG in the rat plasma and tissue homogenate were also validated (as shown in Table 3). The interday and intraday results were within the acceptable criteria (relative standard deviation (RSD\%): <15\%; relative error (RE\%): $\pm 15 \%)$, 


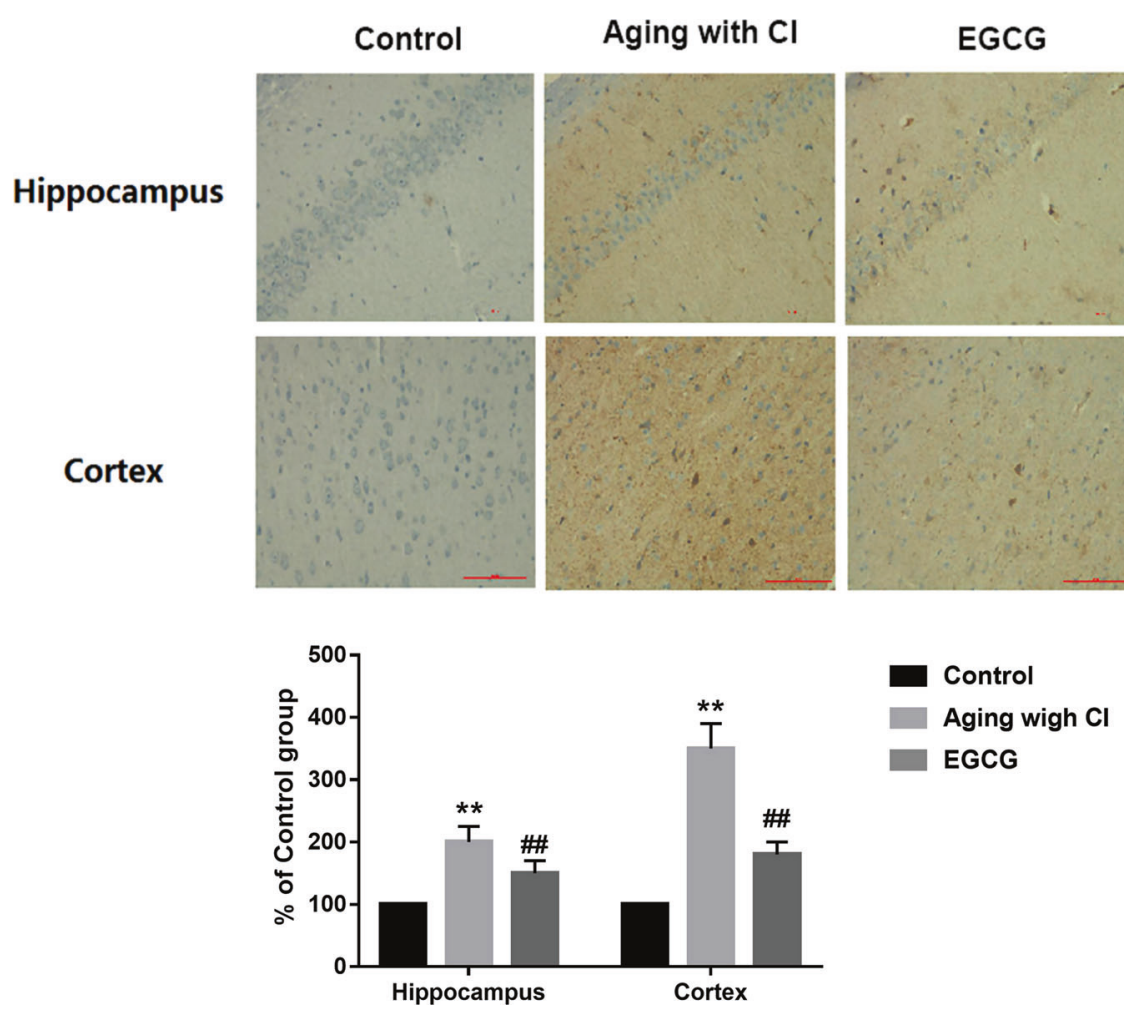

Fig. 4 (-)-Epigallocatechin-3-gallate (EGCG) treatment ameliorated the over-expression of $A \beta_{1-42}$ in the hippocampus and cortex of aging rats with cognitive impairment $(\mathrm{Cl})$ by immunohistochemical staining $(n=6)$. ${ }^{* *} P<0.01$, compared with the control group; ${ }^{\# \#} P<0.01$, compared with the aging with $\mathrm{Cl}$ group

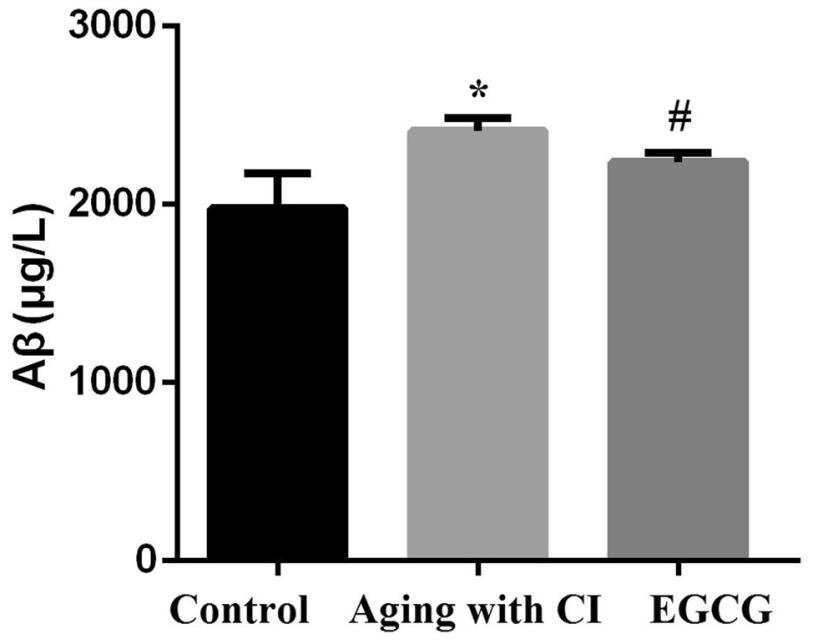

Fig. 5 Enzyme-linked immunosorbent assay (ELISA) of $A \beta$ in the control, the aging with cognitive impairment $(\mathrm{Cl})$ and the (-)-epigallocatechin-3-gallate (EGCG) treatment group $(n=6) .{ }^{*} P<$ 0.05 , compared with the control group; ${ }^{\#} P<0.05$, compared with the aging with $\mathrm{Cl}$ group

the recoveries of the EGCG and IS were consistent and reproducible at different concentration levels in various plasma and tissue homogenate samples, and all matrix effect ratios were between $90 \%$ and $110 \%$. The analyte was considered stable in rat plasma and tissues homogenate under the conditions at room temperature for $24 \mathrm{~h}$, at $-20^{\circ} \mathrm{C}$ for at least 30 days, after three freeze and thaw cycles, and at $4^{\circ} \mathrm{C}$ in an autosampler for $10 \mathrm{~h}$ after preparation (as shown in Table 4).
With the validated UPLC-MS/MS method for the quantitative analysis of EGCG in rat plasma, the mean plasma concentration versus time profiles of EGCG in the control and aging with $\mathrm{Cl}$ groups are illustrated in Fig. 7a. The main pharmacokinetic parameters are summarized in Table 5. Interestingly, compared with the control group, the aging with $\mathrm{Cl}$ group showed a remarkable increase in the $A \cup C_{0-24}, \mathrm{AUC}_{0-\infty}$, and $C_{\max }(P<0.05$, Fig. 7b), suggesting that EGCG absorption in the aging with $\mathrm{Cl}$ group was higher.

After obtaining the pharmacokinetic characteristics of EGCG in rat plasma, we investigated the distribution status of EGCG to further confirm the anti-AD pharmacodynamic basis. EGCG could not be detected in the brains of the control group at 1.0, 2.0, 4.0, and $6.0 \mathrm{~h}$ after EGCG administration; however, excitingly, EGCG appeared in the brains of the aging with $\mathrm{Cl}$ group, and the highest concentration of EGCG was $780 \mathrm{ng} / \mathrm{mL}$ at $2 \mathrm{~h}$ after oral administration of $100 \mathrm{mg} / \mathrm{kg} \mathrm{EGCG}(P<0.01$, Fig. 8). The concentrations of EGCG in the heart, lung, and intestine were higher in the aging with $\mathrm{Cl}$ group than in the control group $(P<0.05$ or $P<0.01$, Fig. 7), and at $2 \mathrm{~h}$ after administration, the EGCG concentration in the heart was higher than that in the other tissues.

BBB permeability was increased in aging rats with $\mathrm{Cl}$ The interesting discovery of the different pharmacokinetic and distribution characteristics of EGCG between groups attracted our attention. In general, as a water-soluble substance, EGCG does not easily pass through the BBB to enter the CNS. However, we found that EGCG was distributed in brain tissues in the aging with $\mathrm{Cl}$ group; therefore, the BBB permeability in the different groups needed to be studied further.

First, an EB assay was applied to investigate BBB permeability. After intravenous administration of $E B$ dye, we found that in the aging with $\mathrm{Cl}$ group, the absorbance of EB was significantly higher than that in the control group $(P<0.01$, Fig. $9 a)$, indicating that the 
1: Quad MRM $152.91>108.9316 \mathrm{eV} . .$.

IS

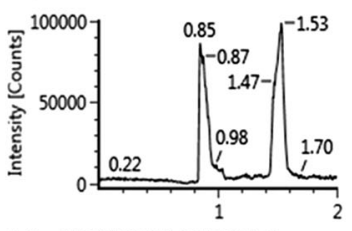

2: Quad MRM 456.94>168.85 14eV...

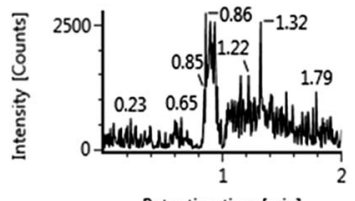

Retention time [min] b 1: Quad MRM 152.91>108.9...

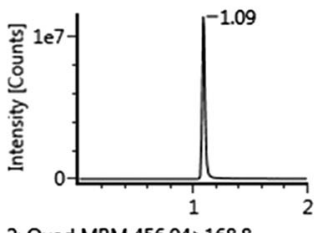

2: Quad MRM 456.94>168.8...

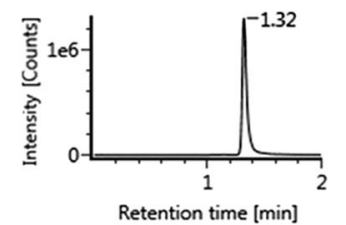

C

1: Quad MRM 152.91>108...

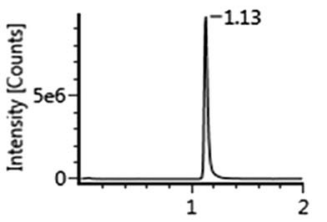

Smoothed : 2: Quad MRM...

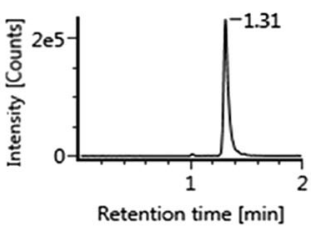

Fig. 6 Representative chromatograms of (-)-epigallocatechin-3-gallate (EGCG) $\left(t_{R}=1.3 \mathrm{~min}\right.$ ) and internal standard (IS) ( $\left.t_{R}=1.1 \mathrm{~min}\right)$. Typical chromatograms of a blank brain homogenate; b blank brain homogenate spiked with EGCG and IS; $\mathbf{c}$ brain homogenate sample $2 \mathrm{~h}$ after administration of EGCG at a dose of $100 \mathrm{mg} / \mathrm{kg}$

\begin{tabular}{|llll|}
\hline $\begin{array}{l}\text { Table 2. Linear ranges, regression equations, and correlation } \\
\text { coefficients of EGCG in rat plasma and tissues }\end{array}$ & $\begin{array}{l}\text { Linear range } \\
\text { Analytes }\end{array}$ & $\begin{array}{l}\text { Regression equation } \\
\left(\times 10^{-3}\right)\end{array}$ & $\begin{array}{l}\text { Correlation } \\
\text { coefficient }(r)\end{array}$ \\
\hline $\begin{array}{l}\text { EGCG } \\
\text { In rat } \\
\text { plasma } \\
\text { In rat } \\
\text { tissues }\end{array}$ & $0.5-2500$ & $y=5.36 x+8.89$ & 0.9982 \\
\hline EGCG (-)-epigallocatechin-3-gallate & $y=1.06 e+003 x-10.60 .9988$ \\
\hline
\end{tabular}

BBB permeability in the aging with $\mathrm{Cl}$ group was greater than that in the control group.

Next, to confirm the physiological ultrastructure of the BBB, we used TEM to detect changes in TJs in brain microvascular endothelial cells of the BBB between the control and aging groups. The BBB is a highly selective barrier critical for CNS homeostasis, and the functional and structural integrity of the BBB mainly relies on specific features of brain microvascular endothelial cells (BMECs). In the control group, the TJs between the BMECs were in close apposition and presented a series of belts. However, in the aging with $\mathrm{Cl}$ group, the integrity of the BBB appeared destroyed, and the TJs were opened (Fig. 9b). The results indicate that the permeability of the BBB was greater in aging rats with $\mathrm{Cl}$.

We also further compared the expression of TJ-associated proteins, such as claudin-5, occludin, and ZO-1, between the control and aging groups. Compared with the control group, the aging with $\mathrm{Cl}$ group expressed significantly lower protein expression levels of claudin-5, occludin, and ZO-1 ( $P<0.01$, Fig. 9c), further confirming that changes in the expression of these proteins contributed to the learning and memory improvement after EGCG treatment in aging rats with $\mathrm{Cl}$.

\section{DISCUSSION}

In the present study, we were first inspired by the different pharmacokinetic and distribution characteristics (brain, heart, lung, intestine, kidney, spleen, testes, and liver) between young rats and aging rats with $\mathrm{Cl}$, which suggested that the increased BBB permeability in aging rats played an important role in the anti-AD efficacy of EGCG treatment demonstrated by improvements in $\mathrm{Cl}$.
Because $A D$ is an age-related progressive neurodegenerative disease clinically characterized by Cls, age is the major risk factor for the disease. $\mathrm{Cl}$, neuropathological changes in aging, and $A D$ have striking similarity; therefore, aging is also thought to be an important risk factor in $A D$. In this study, natural aging rats with $\mathrm{Cl}$ screened with the MWM were employed to mimic the early stage of AD. Previous investigations have noted that senile plaques are responsible for the $\mathrm{Cls}$ and memory decline in normal aging and AD $[19,20]$. Therefore, a deposition was also observed to confirm whether aging rats with $\mathrm{Cl}$ were suitable for further study.

We previously reported that EGCG, the most abundant polyphenol in green tea, significantly improved $\mathrm{Cls}$ and inhibited neuronal apoptosis in amyloid precursor protein/presenilin-1 (APP/PS1) mice and $D$-galactose-induced mice [12, 13]. Other reports also revealed that EGCG inhibits $A \beta_{1-42}$ generation in both murine neuron-like cells (N2a) transfected with APP and in primary neurons derived from APP-overexpressing mice and ameliorates learning and memory impairments in PS2 transgenic mice from TgAPPsw line 2576 [21-23]. The evidence above reliably suggests that EGCG has anti-AD efficacy in vivo and in vitro. However, the mechanism by which EGCG, as a water-soluble component, elicits these anti-AD effects in the CNS has not been elucidated. Researchers have tried to explain the effects of EGCG based on its peripheral effects. One potential mechanism for the beneficial effects of EGCG in the CNS was through its systemic antioxidative and anti-inflammatory functions. EGCG inhibits the release of proinflammatory cytokines (tumor necrosis factor- $a$ (TNF- $\alpha$ ), interleukin-1 $\beta$ (IL-1 $\beta$ ), and IL-6) in lipopolysaccharide (LPS)induced macrophages and neurons and decreases the production of reactive oxygen species in vitro $[24,25]$. In vivo studies have also revealed that EGCG improves LPS-induced cognitive dysfunction in aging rats by preventing LPS-induced activation of astrocytes and decreasing LPS-induced cytokine release, such as IL-1 $\beta$, TNF- $\alpha$, and soluble intercellular adhesion molecule-1 $[26,27]$, indicating that EGCG improves cognitive performance by inhibiting systemic inflammation-induced neuroinflammatory processes. Levites et al. [28] reported that EGCG elicits a neuroprotective effect in the $N$-methyl-4-phenyl-1,2,3,6-tetrahydropyridine-induced mouse model of Parkinson's disease. The authors noted that the neuroprotective effects were unlikely to be caused by monoamine oxidase- $B$ inhibition itself and raised the question of whether EGCG had brain-penetrating properties [28], which attracted our interest.

To answer this question, we focused on the pharmacokinetic characteristics and distribution of EGCG after oral administration at $100 \mathrm{mg} / \mathrm{kg}$. EGCG is well known to be enzymatically unstable 
Table 3. Accuracy, precision, recovery, and matrix effect of EGCG in rat plasma and tissues $(n=6)$

\begin{tabular}{lllllll}
\hline Analytes & Concentration $(\mathrm{ng} / \mathrm{mL})$ & Intra-day RSD $(\%)$ & Inter-day RSD (\%) & Accuracy (RE \%) & Recovery (\%, mean \pm SD) & $\begin{array}{l}\text { Matrix effect }(\%, \text { mean } \pm \\
\text { SD) }\end{array}$ \\
\hline EGCG (in rat plasma) & 25 & 8.4 & 7.8 & 3.7 & $85.2 \pm 4.1$ & $91.3 \pm 2.3$ \\
& 250 & 6.5 & 7.5 & 4.6 & $92.3 \pm 4.4$ & $88.3 \pm 7.2$ \\
& 2000 & 5.7 & 8.8 & -2.1 & $90.3 \pm 3.1$ & $94.7 \pm 6.1$ \\
EGCG (in rat tissue) & 2 & 9.2 & 9.8 & 8.2 & $87.1 \pm 4.6$ & $89.1 \pm 5.3$ \\
& 10 & 6.3 & 7.3 & 5.8 & $96.1 \pm 8.1$ & $91.3 \pm 6.2$ \\
& 200 & 5.2 & 5.8 & -4.2 & $93.2 \pm 6.3$ & $94.2 \pm 4.3$ \\
\hline
\end{tabular}

EGCG (-)-epigallocatechin-3-gallate, RSD relative standard deviation

\begin{tabular}{|c|c|c|c|c|c|c|c|c|c|}
\hline \multirow[t]{3}{*}{ EGCG (plasma) } & 25 & 7.2 & 4.1 & 6.4 & 8.5 & -9.6 & 6.3 & 8.3 & 7.2 \\
\hline & 250 & 3.2 & 3.2 & 1.2 & 3.2 & -7.3 & 9.2 & 5.1 & 4.3 \\
\hline & 2000 & 4.5 & 5.2 & -7.2 & 6.3 & 6.4 & 4.2 & 8.2 & 2.9 \\
\hline \multirow{2}{*}{ EGCG (tissue) } & 10 & 6.8 & 8.2 & 5.8 & 6.2 & -6.2 & 6.3 & 5.2 & 8.2 \\
\hline & 200 & 5.3 & 6.4 & 4.3 & 2.9 & 3.2 & 7.2 & -7.1 & 6.2 \\
\hline
\end{tabular}

EGCG (-)-epigallocatechin-3-gallate, $R S D$ relative standard deviation, $R E$ relative error
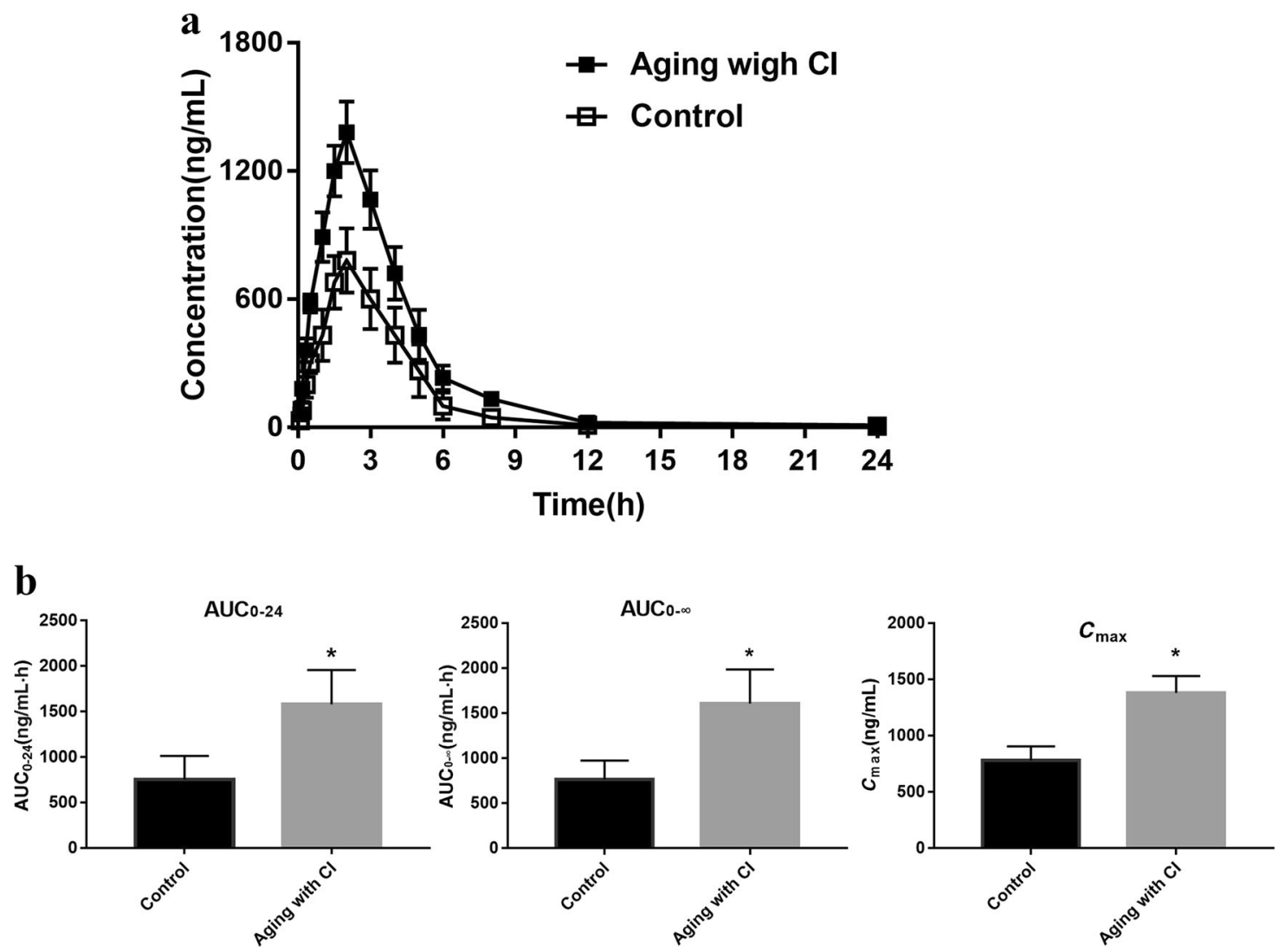

Fig. 7 (-)-Epigallocatechin-3-gallate (EGCG) exhibited different pharmacokinetic manner after the intragastrical administration of EGCG at a dose of $100 \mathrm{mg} / \mathrm{kg}$ between the control and aging with cognitive impairment (CI) groups. a Plasma concentration-time curves for EGCG in the control and aging with $\mathrm{Cl}$ groups (mean $\pm \mathrm{SD}, n=6$ ). $\mathbf{b}$ The calculated pharmacokinetic parameter $A U C_{0-24}, \mathrm{AUC}_{0-\infty}$, and $C_{\max }$ of EGCG in the aging with $\mathrm{Cl}$ group were significantly increased compared with those in the control group. ${ }^{*} P<0.05$, compared with the control group 
1498

because it has many phenyl hydroxyl groups. Therefore, in this test, we added $20 \%$ VC solution in the experimental process to avoid oxidation. The isotope-labeling method, high-performance liquid chromatography coupled to an electrochemical detector, and LC-MS methods have been previously employed for the determination of the EGCG concentration [29-33]. Here, we developed a new sensitive and selective UPLC-MS/MS method for the determination of EGCG in rat plasma and tissues. After oral administration of EGCG at $100 \mathrm{mg} / \mathrm{kg}$, the pharmacokinetic parameters of EGCG were as follows: $C_{\max }$ was $780 \pm 125.2 \mathrm{ng} / \mathrm{mL}$, the $\mathrm{AUC}_{0-24}$ was approximately $754 \pm 259.4 \mathrm{ng} \cdot \mathrm{h} \cdot \mathrm{mL}^{-1}$, and $T_{1 / 2}$ was $5.81 \pm 2.16 \mathrm{~h}$, which were similar to previous findings in rats [3436]. However, our results differed a little from the data obtained from healthy volunteers. Chow et al. [31] found that after $2 \mathrm{mg} / \mathrm{kg}$ EGCG oral administration in healthy volunteers, the AUC was approximately $508.2 \pm 227 \mathrm{ng} \cdot \mathrm{h} \cdot \mathrm{mL}^{-1}, T_{1 / 2}$ was $3.4 \pm 0.3 \mathrm{~h}$, and

Table 5. Main plasma pharmacokinetic parameters of EGCG in the control and aging with $\mathrm{Cl}$ group (mean $\pm \mathrm{SD} ; n=6$ )

\begin{tabular}{|c|c|c|}
\hline \multirow[t]{2}{*}{ Parameters } & \multicolumn{2}{|l|}{ EGCG } \\
\hline & Control group & Aging with $\mathrm{Cl}$ \\
\hline $\mathrm{AUC}_{0-24}\left(\mathrm{ng} \cdot \mathrm{h} \cdot \mathrm{mL}^{-1}\right)$ & $754 \pm 259.4$ & $1581 \pm 377.0^{*}$ \\
\hline$A \cup C_{0-\infty}\left(\mathrm{ng} \cdot \mathrm{h} \cdot \mathrm{mL}^{-1}\right)$ & $766 \pm 208.4$ & $1607 \pm 380.0^{*}$ \\
\hline MRT (h) & $12.09 \pm 2.20$ & $10.93 \pm 1.00$ \\
\hline$T_{1 / 2}(\mathrm{~h})$ & $5.81 \pm 2.16$ & $5.77 \pm 0.70$ \\
\hline$T_{\max }(\mathrm{h})$ & $2.08 \pm 0.49$ & $2.02 \pm 0.42$ \\
\hline$C_{\max }(\mathrm{ng} / \mathrm{mL})$ & $780 \pm 125.2$ & $1380 \pm 150.4^{*}$ \\
\hline $\mathrm{CL}_{Z}\left(\mathrm{~L} \cdot \mathrm{kg}^{-1} \cdot \mathrm{h}^{-1}\right)$ & $1.99 \pm 0.38$ & $5.30 \pm 1.37^{*}$ \\
\hline \multicolumn{3}{|c|}{$\begin{array}{l}A \cup C_{0-24} \text { area under the plasma concentration-time curve from time } 0 \text { to } \\
24 \mathrm{~h}, A U C_{0-\infty} \text { area under the plasma concentration-time curve from time } 0 \\
\text { to } \infty, M R T \text { the mean residence time, } T_{\text {max }} \text { time to reach the maximum } \\
\text { concentration, } C_{\max } \text { peak plasma concentration, } t_{1 / 2} \text { terminal elimination } \\
\text { half-life, } C l \text { plasma clearance, } E G C G(-) \text {-epigallocatechin-3-gallate } \\
{ }^{*} P<0.05 \text { compared with the control group }\end{array}$} \\
\hline
\end{tabular}

$C_{\max }$ was $124.03 \pm 7.86 \mathrm{ng} / \mathrm{mL}$. Naumovski et al. [37] reported that $C_{\max }$ was $824.2 \pm 75.1 \mathrm{ng} / \mathrm{mL}$, the $A U C_{0-8}$ was approximately $173.8 \pm 67.6 \mu \mathrm{g} \cdot \mathrm{h} \cdot \mathrm{mL}^{-1}$, and $T_{1 / 2}$ was $78.6 \pm 94.2 \mathrm{~min}$ after oral administration of $500 \mathrm{mg}$ EGCG capsules [38]. Another group reported that after a single oral dose of EGCG at $200 \mathrm{mg}$ in healthy volunteers, $C_{\max }$ was $73.7 \pm 25.3 \mathrm{ng} / \mathrm{mL}$, the AUC was approximately $22.5 \pm 7.3 \mu \mathrm{g} \cdot \mathrm{min} \cdot \mathrm{mL}^{-1}$, and $T_{1 / 2}$ was $118.0 \pm 77.0 \mathrm{~min}$ [31]. The differences between rats and humans are possibly due to species differences, different dosage regimens, and different formulations [39]. Although there have been many studies on EGCG pharmacokinetics, these studies have focused on the pharmacokinetics in normal animals or healthy volunteers. Physiological conditions or diseases are well known to be able to affect drug disposition; therefore, comparative pharmacokinetics between conditions may be more significant. However, as far as we know, there has been no report investigating the pharmacokinetic characteristics of EGCG in control and aging rats with $\mathrm{Cl}$. We found that after a single orally administered dose of EGCG at $100 \mathrm{mg} / \mathrm{kg}$, the main pharmacokinetic parameters $\mathrm{AUC}_{0-24}$ and $C_{\max }$ in the aging with $\mathrm{Cl}$ group were significantly higher than those in the control group (Fig. 7b), indicating that EGCG had higher absorption in the aging with $\mathrm{Cl}$ group. These results suggest that EGCG might improve learning and memory more efficiently in the $\mathrm{Cl}$ population.

The high absorption of EGCG in aging rats with $\mathrm{Cl}$ could not explain the mechanism of anti-AD efficacy in the CNS alone. Therefore, a distribution study was carried out for further explanation. Dramatically, EGCG appeared in the brains of the aging with $\mathrm{Cl}$ group, but was not detected in the control group (Fig. 8), suggesting that EGCG was able to penetrate the BBB and enter the CNS to elicit anti-AD effects. Until now, there has not been an in vivo study of the distribution of EGCG in the $\mathrm{Cl}$ population. However, Suganuma et al. [29] reported that as a cancer preventive agent, $\left[{ }^{3} \mathrm{H}\right] \mathrm{EGCG}$ was synthesized with a specific activity of $48.1 \mathrm{GBq} / \mathrm{mmol}$ and administered to CD-1 mice to study the distribution status and found that EGCG appeared in brain tissue after high-level intake of EGCG by radioactivity analysis. Their results may differ from ours due to the high dose administered for cancer therapy and the different strain of rats.
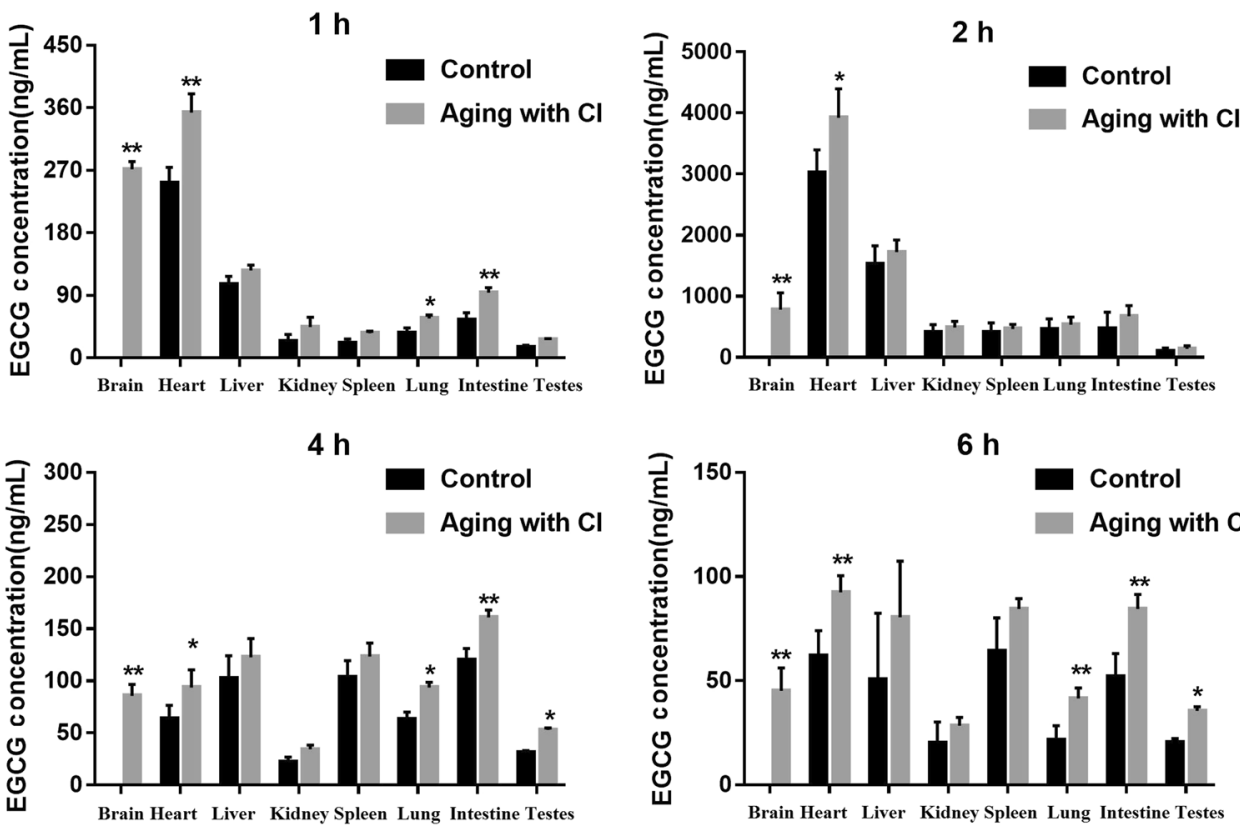

Fig. 8 (-)-Epigallocatechin-3-gallate (EGCG) had different tissue distribution in brain and other tissues after EGCG treatment at 1.0, 2.0, 4.0, and $6.0 \mathrm{~h}$ in the control and aging with cognitive impairment $(\mathrm{Cl})$ groups. ${ }^{*} P<0.05,{ }^{* *} P<0.01$, compared with the control group 
a

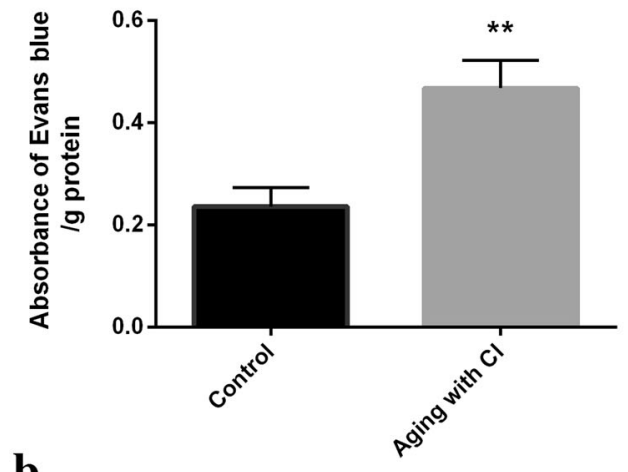

b
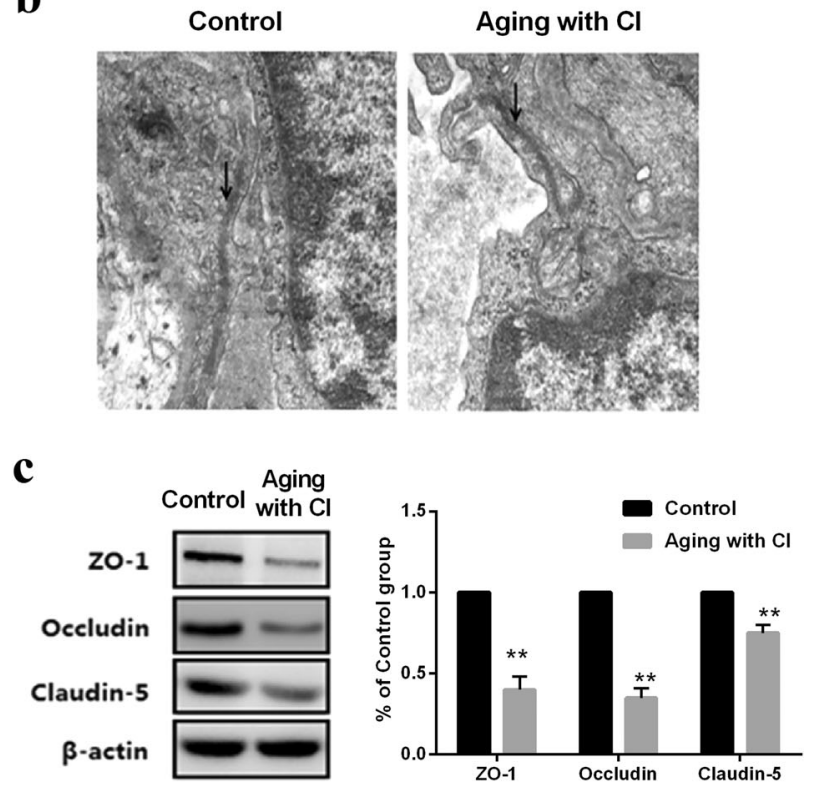

Fig. 9 The permeability of blood-brain barrier (BBB) was apparently increased in the aging with cognitive impairment $(\mathrm{Cl})$ groups. a The absorbance of EB staining was increased in the aging with $\mathrm{Cl}$ groups $(n=6)$. b The ultra-structures of tight junctions (TJs) of BBB in the aging with $\mathrm{Cl}$ groups were changed by transmission electron microscopy (TEM) scanning. c The expressions of the TJ-associated proteins, such as claudin-5, occludin, and ZO-1 were downregulated in the aging with $\mathrm{Cl}$ groups. ${ }^{* *} P<0.01$, compared with the control group

Because EGCG absorption was increased and could be detected in the brains of aging rats with $\mathrm{Cl}$, changes in $\mathrm{BBB}$ permeability were further investigated. Pervin et al. [40] found that approximately $2.8 \%$ EGCG reached brain parenchyma in 30 min using an in vitro BBB model, but this had not been examined in vivo until now. We first systemically investigated the BBB permeability of EGCG in vivo. The exudation of EB dye was significantly higher in the aging with $\mathrm{Cl}$ group than in the control group, indicating that BBB leakage might exist in the CNS of the rats in the aging with $\mathrm{Cl}$ group. The ultrastructure of the BBB demonstrated by TEM also exhibited abnormal TJs and damaged BBB integrity. Accumulating evidence indicates that claudin-5, occludin, and ZO-1 are critical for the maintenance of barrier function [41-45]. Decreased expression of TJ-related proteins, such as claudin-5, occludin, and ZO-1, further confirmed the increased permeability of the BBB in the aging group. These results provide meaningful evidence of the physiological structural basis for the anti-AD pharmacodynamics of EGCG.

In summary, we first found different pharmacokinetic and distribution characteristics between young rats and aging rats with $\mathrm{Cl}$ and showed that an increase in BBB permeability was the physiological basis for the cognitive improvement observed after EGCG treatment, providing powerful evidence that EGCG may be used as drug to treat many neurodegenerative diseases.

\section{ACKNOWLEDGEMENTS}

This work is supported by National Natural Science Foundation of China (81703519) and Scientific Research Project of Liaoning Province (20170520257).

\section{AUTHOR CONTRIBUTIONS}

BBW conceived and designed the experiments; BBW, XZ, and WFY performed the experiments; MYL analyzed the data; MJW wrote and reviewed the paper. All authors read and approved the final manuscript.

\section{ADDITIONAL INFORMATION}

Competing interests: The authors declare no competing interests.

\section{REFERENCES}

1. Querfurth HW, Laferla FM. Alzheimer's disease. N Eng J Med. 2010;362:329-44.

2. Wang XP, Ding HL. Alzheimer's disease: epidemiology, genetics, and beyond. Neurosci Bull. 2008;24:105-9.

3. Tanzi RE, Bertram L. Twenty years of the Alzheimer's disease amyloid hypothesis: a genetic perspective. Cell. 2005;120:545-55.

4. O'Brien RJ, Wong PC. Amyloid precursor protein processing and Alzheimer's disease. Annu Rev Neurosci. 2011;34:185-204.

5. Yardin C. Histopathology of Alzheimer's disease. Morphologie. 2007;91:199-201.

6. Hirtz D, Thurman DJ, Gwinn-Hardy K, Mohamed M, Chaudhuri AR, Zalutsky R. How common are the "common" neurologic disorders? Neurology. 2007;68:326-37.

7. Alzheimer's disease international. World Alzheimer Report, 2009, Executive Summary[R]. London, 2009.

8. Higuchi A, Yonemitsu K, Koreeda A, Tsunenari S. Inhibitory activity of epigallocatechin gallate $(\mathrm{EGCg})$ in paraquat-induced microsomal lipid peroxidation-a mechanism of protective effects of EGCg against paraquat toxicity. Toxicology. 2003;183:143-49.

9. Landis-Piwowar KR, Huo C, Chen D, Milacic V, Shi G, Chan TH, et al. A novel prodrug of the green tea polyphenol (-)-epigallocatechin-3-gallate as a potential anticancer agent. Cancer Res. 2007;67:4303-10.

10. Wolfram S. Effects of green tea and EGCG on cardiovascular and metabolic health. J Am Coll Nutr. 2007;26:373S-388S.

11. Ahmed S, Pakozdi A, Koch AE. Regulation of interleukin-1beta-induced chemokine production and matrix metalloproteinase 2 activation by epigallocatechin-3gallate in rheumatoid arthritis synovial fibroblasts. Arthritis Rheum. 2006;54:2393-401.

12. He M, Zhao L, Wei MJ, Yao WF, Zhao HS, Chen FJ. Neuroprotective effects of (-)-epigallocatechin-3-gallate on aging mice induced by $D$-galactose. Biol Pharm Bull. 2009:32:55-60.

13. Liu MY, Chen FJ, Sha L, Wei MJ. (-)-Epigallocatechin-3-gallate ameliorates learning and memory deficits by adjusting the balance of TrkA/p75NTR signaling in APP/PS1 transgenic mice. Mol Neurobiol. 2014;49:1350-63.

14. Yang SL, Liu MY, Zhong $X$, Du K, Wei MJ. EGCG ameliorating learning and memory impairment in APP /PS1 mice by inhibiting $p 75^{\text {NTR }}$ pathway. Chin Pharm Bull. 2014;30:1419-24.

15. Rezai-Zadeh K, Arendash GW, Hou H, Fernandez F, Jensen M, Runfeldt M, et al. Green tea epigallocatechin-3-gallate (EGCG) reduces beta-amyloid mediated cognitive impairment and modulates tau pathology in Alzheimer transgenic mice. Brain Res. 2008;12:177-87.

16. Lee JW, Lee YK, Ban JO, Ha TY, Yun YP, Han SB, et al. Green tea (-)-epigallocatechin-3-gallate inhibits $\beta$-amyloid induced cognitive dysfunction through modification of secretase activity via inhibition of ERK and NF-KB pathways in mice. J Nutr. 2009;139:1987-93.

17. Guidance for Industry, Bioanalytical Method Validation. http://www.fda.gov/cder/ guidance/index.htm. Updated 2001.

18. ICH, Harmonised Tripartite Guideline, Validation of Analytical Procedure: Methodology. International Conference on Harmonisation of Technical Requirements for Registration of Pharmaceuticals for Human Use, Geneva, Switzerland, 1996.

19. Jiménez-Rubio G, Herrera-Pérez JJ, Hernández-Hernández OT, Martínez-Mota L. Relationship between androgen deficiency and memory impairment in aging and Alzheimer's disease. Acta Esp Psiquiatr. 2017;45:227-47. 
20. Jansen WJ, Wilson RS, Visser PJ, Nag S, Schneider JA, James BD, et al. Age and the association of dementia-related pathology with trajectories of cognitive decline. Neurobiol Aging. 2017;61:138-45.

21. Rezai-Zadeh K, Shytle D, Sun N, Mori T. Green tea epigallocatechin-3-gallate (EGCG) modulates amyloid precursor protein cleavage and reduces cerebral amyloidosis in Alzheimer transgenic mice. J Neurosci. 2005;25:8807-14.

22. Lee J, Lee W, Ban YK, Ha JO. Green tea (-)-epigallocatechin-3-gallate inhibits beta-amyloid-induced cognitive dysfunction through modification of secretase activity via inhibition of ERK and NF-kappaB pathways in mice. J Nutr. 2009;139:1987-93.

23. Lee JH, Moon JH, Kim SW, Jeong JK, Nazim UM, Lee YJ, et al. EGCG-mediated autophagy flux has a neuroprotection effect via a class III histone deacetylase in primary neuron cells. Oncotarget. 2015;6:9701-17.

24. Wu YR, Choi HJ, Kang YG, Kim JK, Shin JW. In vitro study on anti-inflammatory effects of epigallocatechin-3-gallate-loaded nano- and microscale particles. Int J Nanomed. 2017;12:7007-13.

25. Liu JB, Zhou L, Wang YZ, Wang $X$, Zhou $Y$, Ho WZ, et al. Neuroprotective activity of (-)-epigallocatechin gallate against lipopolysaccharide-mediated cytotoxicity. J Immunol Res. 2016;2016:4962351.

26. Yamanaka D, Kawano T, Nishigaki A, Aoyama B, Tateiwa H, Shigematsu-Locatelli $M$, et al. Effects of epigallocatechin-3-gallate on systemic inflammation-induced cognitive dysfunction in aged rats. J Anesth. 2017;31:726-35.

27. Lee YJ, Choi DY, Yun YP, Han SB, Oh KW, Hong JT. Epigallocatechin-3-gallate prevents systemic inflammation-induced memory deficiency and amyloidogenesis via its anti-neuroinflammatory properties. J Nutr Biochem. 2013;24:298-310.

28. Levites Y, Weinreb O, Maor G, Youdim MB, Mandel S. Green tea polyphenol (-)-epigallocatechin-3-gallate prevents $N$-methyl-4-phenyl-1,2,3,6-tetrahydropyridine-induced dopaminergic neurodegeneration. J Neurochem. 2001;78:1073-82.

29. Suganuma M, Okabe S, Oniyama M, Tada $Y$, Ito H, Fujiki H. Wide distribution of $\left[{ }^{3} \mathrm{H}\right](-)$-epigallocatechin gallate, a cancer preventive tea polyphenol, in mouse tissue. Carcinogenesis. 1998;19:1771-6.

30. Lee MJ, Maliakal P, Chen L, Meng X, Bondoc FY, Prabhu S, et al. Pharmacokinetics of tea catechins after ingestion of green tea and (-)-epigallocatechin-3-gallate by humans: formation of different metabolites and individual variability. Cancer Epidemiol Biomark Prev. 2002;11:1025-32.

31. Chow HH, Cai Y, Alberts DS, Hakim I, Dorr R, Shahi F, et al. Phase I pharmacokinetic study of tea polyphenols following single-dose administration of epigallocatechin gallate and polyphenon E. Cancer Epidemiol Biomark Prev. 2001;10:53-8.
32. Zhu M, Chen Y, Li RC. Pharmacokinetics and system linearity of tea catechins in rat. Xenobiotica. 2001;31:51-60.

33. Gawande S, Kale A, Kotwal S. Effect of nutrient mixture and black grapes on the pharmacokinetics of orally administered (-)epigallocatechin-3-gallate from green tea extract: a human study. Phytother Res. 2008;22:802-8.

34. Chen L, Lee MJ, Li H, Yang CS. Absorption, distribution, elimination of tea polyphenols in rats. Drug Metab Dispos. 1997;25:1045-50.

35. Oritani $Y$, Setoguchi $Y$, Ito $R$, Maruki-Uchida $H$, Ichiyanagi $T$, Ito $T$. Comparison of (-)-epigallocatechin-3-O-gallate (EGCG) and O-methyl EGCG bioavailability in rats. Biol Pharm Bull. 2013;36:1577-82.

36. Smith AJ, Kavuru P, Arora KK, Kesani S, Tan J, Zaworotko MJ, et al. Crystal engineering of green tea epigallocatechin-3-gallate (EGCG) cocrystals and pharmacokinetic modulation in rats. Mol Pharm. 2013;10:2948-61.

37. Naumovski N, Blades BL, Roach PD. Food inhibits the oral bioavailability of the major green tea antioxidant epigallocatechin gallate in humans. Antioxidants (Basel). 2015;4:373-93.

38. Zhang $L$, Han $Y, X u L$, Liang $Y, C$ Chen $X$, Li J, et al. The effects of co-administration of butter on the absorption, metabolism and excretion of catechins in rats after oral administration of tea polyphenols. Food Funct. 2015;6:2249-56.

39. Draijer R, Duchateau GS. Capsule formats may hamper green tea catechin bioavailability. J Nutr. 2015;145:2797-8.

40. Pervin $M$, Unno $K$, Nakagawa A, Takahashi $Y$, Iguchi $K$, Yamamoto $H$, et al. Blood-brain barrier permeability of (-)-epigallocatechin gallate, its proliferationenhancing activity of human neuroblastoma SH-SY5Y cells, and its preventive effect on age-related cognitive dysfunction in mice. Biochem Biophys Rep. 2017;9:180-6.

41. Persidsky Y, Ramirez SH, Haorah J, Kanmogne GD. Blood-brain barrier: structural components and function under physiologic and pathologic conditions. J Neuroimmune Pharm. 2006;1:223-36.

42. Sandoval KE, Witt KA. Blood-brain barrier tight junction permeability and ischemic stroke. Neurobiol Dis. 2008;32:200-19.

43. Hsdkins J, Gu L, Wittchen E. ZO-3, a novel member of the MAGUK protein family found at the tight junction, interacts with ZO-1 and occludin. J Cell Biol. 1998;141:199-208.

44. Itoh $M$, Furose $M$, Morita K. Direct binding of three tight junction-associated MAGUKs, ZO-1, ZO-2 and ZO-3, with the COOH termini of claudins. J Cell Biol. 1999;147:1351-63.

45. Morita K, Itoh M, Saitou M. Subcellular distribution of tight junction-associated proteins (occludin, ZO-I, ZO-2) in rodent skin. J Invest Dermatol. 1998;110:862-6. 